\title{
RhD blood type significantly influences susceptibility to contract COVID-19 among a study population in Iraq [version
}

\section{1; peer review: 1 approved]}

\author{
Khalid R Majeed (D1, Dhurgham Al-Fahad (iD)2, Hayder H Jalood3, \\ Haider A Hantosh ${ }^{4}$, Mrtatha K Ali ${ }^{5}$, Sumiktsal Sakthivel ${ }^{6}$, Harry F Williams ${ }^{7}$, \\ Jonathan M Gibbins ${ }^{8}$, Ketan Patel ${ }^{8}$, M. Fazil Baksh9, Sakthivel Vaiyapuri (iD10 \\ ${ }^{1}$ Department of Medical Laboratory Technique, Al-Nasiriyah Technical Institute, Southern Technical University, Thi-Qar, Iraq \\ ${ }^{2}$ Department of Pathological Analysis, College of Science, University of Thi-Qar, Thi-Qar, Iraq \\ ${ }^{3}$ General Directorate of Education in Thi-Qar Province, Thi-Qar, Iraq \\ ${ }^{4}$ Thi-Qar Health Directorate, Thi-Qar, Iraq \\ ${ }^{5}$ College of Agriculture, University of Wasit, Wasit, Iraq \\ ${ }^{6}$ Reading School, Reading, UK \\ ${ }^{7}$ Toxiven Biotech Private Limited, Coimbatore, Tamil Nadu, India \\ ${ }^{8}$ School of Biological Sciences, University of Reading, Reading, UK \\ ${ }^{9}$ Department of Mathematics and Statistics, University of Reading, Reading, UK \\ ${ }^{10}$ School of Pharmacy, University of Reading, Reading, UK
}

V1 First published: $21 \mathrm{Jan} 2021$, 10:38

https://doi.org/10.12688/f1000research.27777.1

Latest published: $21 \mathrm{Jan} 2021,10: 38$

https://doi.org/10.12688/f1000research.27777.1

\section{Abstract}

The ABO blood type has been reported to be associated with several diseases such as hepatitis and malaria. Recently, some studies have reported that people with O blood type are protected against COVID19 , while people with A blood type are more susceptible to contract this disease. Here, we analysed data from 5668 COVID-19 patients along with the same number of control samples in a study population in Iraq. Our analysis confirms that people with O blood type are protected partially against COVID-19. Notably, we demonstrate that people with RhD- are more susceptible to contract COVID-19 than people with RhD+ blood type. The blood types are associated with some clinical symptoms such as headache and asthenia of COVID-19, but there is no association with other symptoms. There is no association between blood types and deaths among COVID-19 patients. This study suggests that in addition to ABO, RhD blood type influences the susceptibility to contract COVID-19. Overall, we conclude that susceptibility/protection against COVID-19 may not be determined based only on blood types among the global population as this might vary based on a number of other factors such as ethnicity, geographical locations, occupation and the level of exposure to infected people.

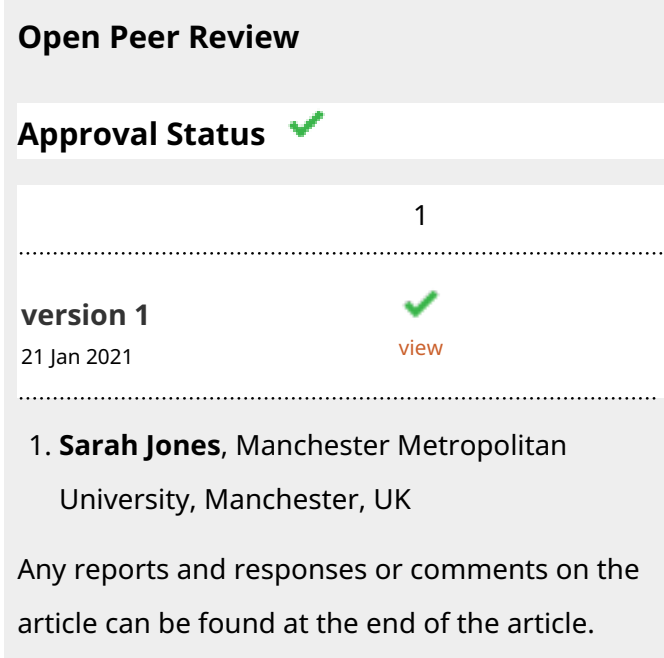




\section{Keywords}

COVID-19, ABO, RhD, Blood type, Risk factors, Blood group, Red blood

cells, Iraq

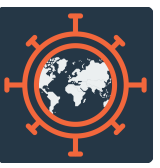

This article is included in the Emerging Diseases

and Outbreaks gateway.

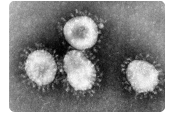

This article is included in the Coronavirus

collection.

Corresponding author: Sakthivel Vaiyapuri (s.vaiyapuri@reading.ac.uk)

Author roles: Majeed KR: Data Curation; Al-Fahad D: Conceptualization, Data Curation, Investigation, Methodology, Project Administration, Resources, Supervision, Writing - Review \& Editing; Jalood HH: Data Curation; Hantosh HA: Data Curation; Ali MK: Data Curation; Sakthivel S: Writing - Original Draft Preparation, Writing - Review \& Editing; Williams HF: Writing - Original Draft Preparation, Writing - Review \& Editing; Gibbins JM: Validation, Writing - Review \& Editing; Patel K: Conceptualization, Investigation, Methodology, Resources, Validation, Writing - Review \& Editing; Baksh MF: Conceptualization, Formal Analysis, Investigation, Methodology, Resources, Software, Validation, Visualization, Writing - Original Draft Preparation, Writing - Review \& Editing; Vaiyapuri S: Conceptualization, Data Curation, Formal Analysis, Investigation, Methodology, Project Administration, Resources, Supervision, Validation, Visualization, Writing - Original Draft Preparation, Writing - Review \& Editing

Competing interests: No competing interests were disclosed.

Grant information: The author(s) declared that no grants were involved in supporting this work.

Copyright: ( 2021 Majeed KR et al. This is an open access article distributed under the terms of the Creative Commons Attribution License, which permits unrestricted use, distribution, and reproduction in any medium, provided the original work is properly cited.

How to cite this article: Majeed KR, Al-Fahad D, Jalood HH et al. RhD blood type significantly influences susceptibility to contract COVID-19 among a study population in Iraq [version 1; peer review: 1 approved] F1000Research 2021, 10:38 https://doi.org/10.12688/f1000research.27777.1

First published: 21 Jan 2021, 10:38 https://doi.org/10.12688/f1000research.27777.1 


\section{Introduction}

COVID-19 is caused by the newly identified severe acute respiratory syndrome coronavirus-2 (SARS-CoV-2), which initiated a pandemic in early $2020^{1,2}$. Following initial infections in Wuhan, Hubei Province of China, it has affected almost all countries in the world, resulting in a significant number of deaths (over 1.1 million until October 2020) and increased economic burden worldwide. The primary symptoms of COVID-19 include a fever, persistent cough, dyspnoea, thrombosis, myalgia, fatigue, and, in some cases, decreased white blood cell count and severe pneumonia, which requires mechanical ventilation and other intensive care support. Although the relationship between ABO blood types and various diseases is poorly understood, blood types have been reported to be associated with several diseases caused by organisms such as SARS-CoV- $1^{3}$, Helicobacter pylori $^{4}$, hepatitis B virus ${ }^{5}$, Norwalk virus ${ }^{6}$, rotavirus and dengue virus, as well as malaria ${ }^{7}$. Similarly, the potential importance of $\mathrm{ABO}$ blood types in relevance to contracting COVID-19 has been sparsely reported. While some studies found no significant correlation between blood types and the impact of COVID-19 $9^{8-10}$, others have reported that people with O blood type are partially protected against COVID-19 infection and people with $\mathrm{A}$ or $\mathrm{AB}$ blood type are more susceptible to this disease $^{11-16}$. This could be due to the presence of anti- $\mathrm{A}^{17}$ and/or anti-B antibodies in the circulation and their ability to bind to the spike proteins of the virus, thereby preventing them entering cells and proliferating. Notably, a genome wide association study has confirmed the potential involvement of the ABO blood group system in contracting COVID-19 ${ }^{18}$. Although few studies have specifically established an association between $\mathrm{RhD}$ blood type and susceptibility to COVID-19, a recent study reported a high risk association between $\mathrm{RhD}+$, COVID-19 infection and resulting deaths ${ }^{13}$. However, the robust correlation between the blood types specifically RhD and COVID-19 infection has not yet been fully established. Hence, we explored the potential association between blood types, particularly $\mathrm{RhD}$ and COVID-19 in a study population of Iraq.

\section{Methods}

The aim of this study was to analyse the relationship between the blood types and COVID-19 associated complications in a small population of Iraq. Therefore, in this study, we collected data (i.e. blood group, primary symptoms, previous risk factors, age, gender and outcomes, severity level of COVID-19) from the records of 5,668 COVID-19 patients (confirmed as positive by real-time polymerase chain reaction and this was considered as the key criteria for eligibility to be included in this study) who were admitted to Al-Hussein Teaching Hospital, Thi-Qar and Alkarama Teaching Hospital, Wasit in Iraq between March and June 2020. Blood type data, were collected from the same number of control (non-COVID-19) individuals from the same hospitals (using their records database) and matched by age and gender to the cases.

The sample size was based on the number of COVID-19 patients admitted in these two hospitals during the study period. The accuracy of data was thoroughly checked by healthcare professionals working in these hospitals and the authors prior to analysis. The individuals who were involved in data collection did not directly analyse the data. The data analysis (between COVID-19 and non COVID-19 groups) was performed by different authors using anonymised data in order to avoid any potential bias. All the statistical analyses were performed using Pearson's Chi-square test and logistic regression models in R statistical package (www.r-project.org).

This study design, data collection and consent were approved by the ethical committee (Ref no: 00563477) at Thi-Qar Health Directorate, the Ministry of Health, Republic of Iraq, and all the data were anonymised prior to analysis. Informed verbal consent was obtained from all patients to use their records, and where patients were minor (below 18 years old), consent was obtained from their parents or legal guardians. Verbal consent instead of written consent was obtained as the hospitals were very busy, as a result of the pandemic. Appropriate permissions from the hospitals were also obtained to use the anonymised data for this study.

\section{Results}

The COVID-19 population studied here consisted of 3691 (65.2\%) males and 1977 (34.8\%) females. According to age group: $\leq 10$ years, 267 (4.7\%); 11-20 years, 511 (9\%); 21-30 years, 1781 (31.4\%); 31-40 years, 1221 (21.5\%); 41-50 years, 870 (15.3\%); 51-60 years, 569 (10\%); 61-70 years, 273 (4.8\%); 71-80 years, $138(2.4 \%)$; 81-90 years, $32(0.6 \%)$; 90+ years, $6(0.1 \%)$ (with the highest age being 100). The median age of the population was 33 years, and the most infected age group in this population was $21-30$ years old.

Among COVID-19 patients, 1572 (27.7\%) had blood type A $(\mathrm{A}+=1493 ; \mathrm{A}-=79), 1880(33.2 \%)$ had $\mathrm{B}(\mathrm{B}+=1653 ; \mathrm{B}-=$ 227), $645(11.4 \%)$ had $\mathrm{AB}(\mathrm{AB}+=511 ; \mathrm{AB}-=134)$ and 1571 $(27.7 \%)$ had $\mathrm{O}(\mathrm{O}+=1495 ; \mathrm{O}-=76)$. The control population (5668, matched for age and sex) had a similar ratio of blood types [1454 (25.7\%) people had A $(\mathrm{A}+=1405 ; \mathrm{A}-=49) ; 1792$ $(31.6 \%)$ had $\mathrm{B}(\mathrm{B}+=1692 ; \mathrm{B}-=100) ; 411(7.3 \%)$ had $\mathrm{AB}$ $(\mathrm{AB}+=366 ; \mathrm{AB}-=45) ; 2011(35.5 \%)$ had $\mathrm{O}(\mathrm{O}+=1976$; $\mathrm{O}-=35)]$. Among the control population, $\mathrm{O}+$ was the most common blood type, and $\mathrm{O}$ - was the least common type with others being small population groups except $\mathrm{A}+$ and $\mathrm{B}+$.

There is very strong evidence $\left(\mathrm{X}^{2}=209.51\right.$, $\left.\mathrm{df}=8, p<0.0001\right)$ for association between blood groups and COVID-19 infection among the study population. Exploring this association further demonstrates that the proportion of COVID-19 patients with $\mathrm{O}+$ blood type is significantly lower than the control population, suggesting that this blood type is protective against this disease. In contrast, $\mathrm{A}-, \mathrm{AB}-, \mathrm{AB}+, \mathrm{B}-$ and $\mathrm{O}-$ have shown increased susceptibility to COVID-19 compared to the control population (Figure 1A). Notably, COVID-19 patients with $\mathrm{A}+$ and $\mathrm{B}+$ blood types did not show any significant difference in the proportion infected when compared to the control group (Figure 1B). The risk of contracting COVID-19 was higher among $\mathrm{RhD}$ - patients compared to the $\mathrm{RhD}+$ patients $[\mathrm{OR}=2.38,95 \% \mathrm{CI}(2.03,2.79), p=0.0001]$. There is no evidence for association between gender and blood type among COVID-19 patients $\left(\mathrm{X}^{2}=4.97, \mathrm{df}=7, p=0.664\right)$. 

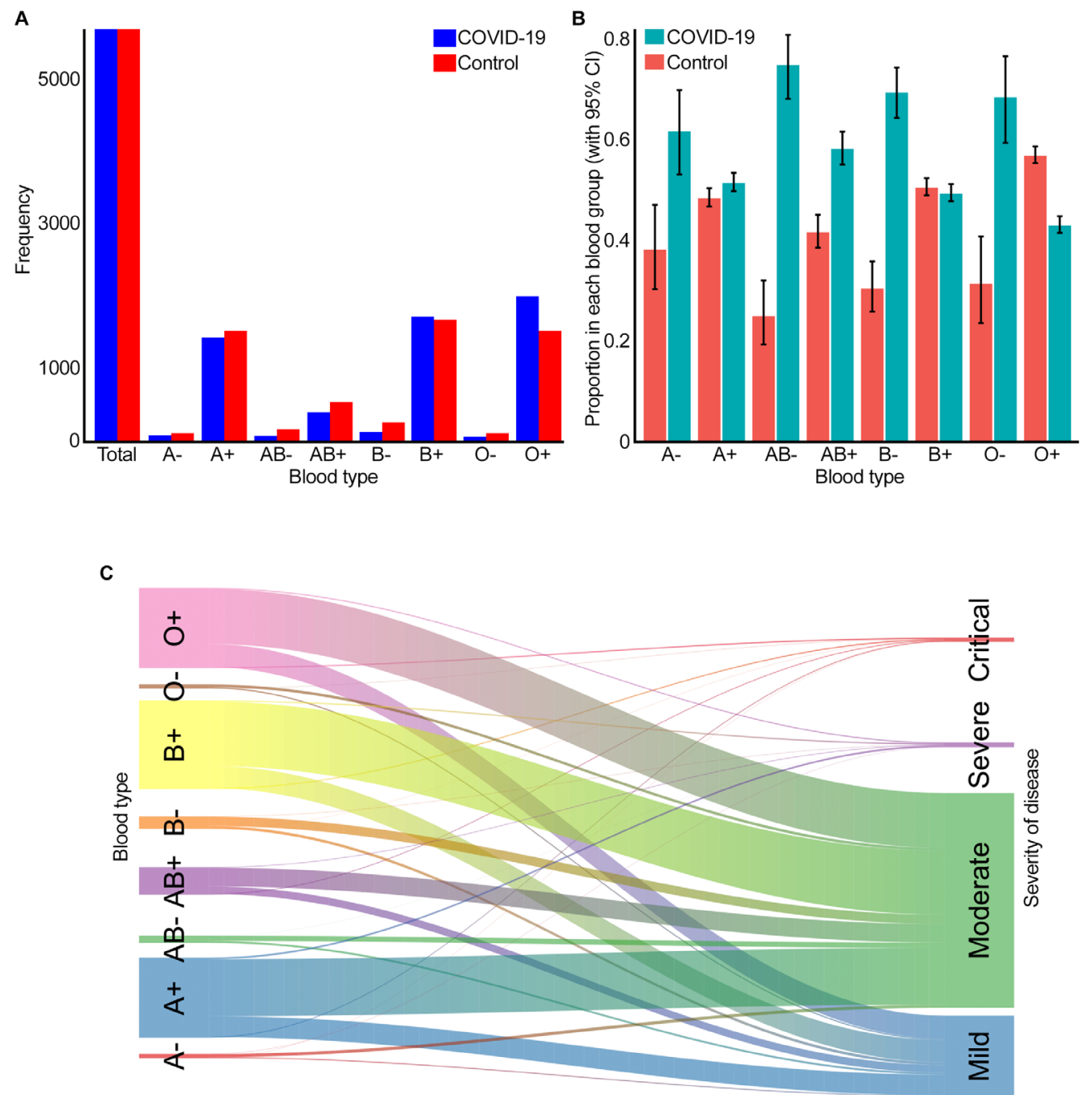

Figure 1. Frequency and proportion of various blood types in relation to COVID-19 and its severity. (A) the frequency of different blood types in the study population. (B) the proportions of controls and COVID-19 cases within different blood types. (C) the Sankey plot shows the relationship between blood types and severity of COVID-19 among the study population.

The Sankey plot (Figure 1C) illustrates the association between different blood types and the severity of COVID-19 among patients (the severity level was classified according to the guidelines provided by the Ministry of Health in Iraq). In total, there were 77 patients classified as in 'critical' stage, and all of them died in hospital during treatment. A total of 90 patients were in the 'severe' category, of which only 4 recovered while the others died in hospitals. A further 4000 were in the 'moderate' category and 1501 patients were listed as 'mild'. Based on our analysis, there was no significant association between blood types and the severity of disease among these patients.

There is evidence for the association of some clinical symptoms with certain blood types among COVID-19 patients when adjusted for age, gender, severity of disease and risk factors. For example, asthenia is significantly lower in people with blood type $\mathrm{B}+$ compared to individuals with $\mathrm{O}+[\mathrm{OR}=0.98,95 \%$ CI $(0.96,0.99), p=0.004]$. Similarly, experiencing a headache was significantly lower in people with blood type $\mathrm{AB}+$ compared to people with $\mathrm{O}+[\mathrm{OR}=0.97,95 \% \mathrm{CI}(0.95,0.99)$, $p=0.012]$. It is noteworthy that the size of these effects is very small. There is no significant correlation between other clinical symptoms (such as fever, chills, cough, dyspnea, anosmia ageusia, loss of appetite, muscle ache, cyanosis, rhinorrhoea, sore throat, diarrhoea, nausea and vomiting) and blood types.

In total, 176 deaths were recorded in this study among COVID-19 patients. However, there is no evidence for association of blood types, including $\mathrm{RhD}$, with death due to COVID-19 when adjustments were made for age, gender and risk factors $\left(\mathrm{X}^{2}=0.037, \mathrm{df}=7, p=0.999\right)$. The 172 patients who died were reported to have various preexisting health conditions as risk 
factors. For example, 63 patients had hypertension, 19 had type 2 diabetes and hypertension, 33 had only diabetes, 1 had type 2 diabetes with acute renal failure, 1 had type 2 diabetes with atherosclerosis and another had diabetes with chronic kidney disease. Notably, 18 patients had chronic obstructive pulmonary disease (COPD), 3 had COPD with diabetes, and one had COPD with hypertension. Another 3 patients had chronic kidney disease and 1 had chronic lung disease. In total, 17 patients had hypertension while 4 had acute renal failure and 4 had acute pulmonary conditions. Of the 5668 patients, only 37 were asymptomatic (hence fewer admission in hospitals) and others had one or more notable COVID-19 symptoms.

\section{Discussion}

The ABO blood types are known to be associated with several human diseases ${ }^{3-7}$. Similar to previous studies ${ }^{12,13}$, here we report that $\mathrm{O}+$ blood type provides partial protection against COVID-19. While the association between RhD blood type and various diseases has not been fully established yet, RhD+ has been reported to be associated with high infection and death rate among COVID-19 patients in a population in the USA ${ }^{13}$. In contrast to this previous study ${ }^{13}$, interestingly, we report the significance of RhD blood type in influencing the susceptibility to contract COVID-19 among this study population; i.e. people with RhD- blood were more susceptible to contract COVID-19 than people with $\mathrm{RhD}+$ blood type. The mechanisms behind this protection/susceptibility are unclear and further research is warranted to unravel the underlying questions. Moreover, we emphasise that the association between blood types (ABO and $\mathrm{RhD}$ ) and COVID-19 is likely to be based on numerous factors including (but not limited to) ethnicity, geographical location, nature of occupation and the exposure to infected patients.

\section{Data availability}

Underlying data

University of Reading Research Data Archive: Blood types and their relationship with COVID-19 among a study population in Iraq, http://dx.doi.org/10.17864/1947.278 ${ }^{19}$.

Data are available under the terms of the Creative Commons Attribution 4.0 International license (CC-BY 4.0).

\section{Acknowledgements}

We would like to thank Abbas J. Hadi from the Thi-Qar Directorate of Public Health, Al-Hussein Teaching Hospital, Thi-Qar and Alkarama Teaching Hospital, Wasit, Iraq for providing all the data used in this study and their constant support.
1. WHO: Novel Coronovirus (2019-nCoV) Situation Report - 1. World Health Organisation.

Reference Source

2. Phelan AL, Katz R, Gostin LO: The Novel Coronavirus Originating in Wuhan, China: Challenges for Global Health Governance. JAMA. 2020; 323(8): 709-710.

PubMed Abstract | Publisher Full Text

3. Cheng Y, Cheng G, Chui CH, et al:: ABO Blood Group and Susceptibility to Severe Acute Respiratory Syndrome. JAMA. 2005; 293(12): 1447-1451. PubMed Abstract | Publisher Full Text

4. Boren T, Falk P, Roth KA, et al.: Attachment of Helicobacter pylori to human gastric epithelium mediated by blood group antigens. Science. 1993; 262(5141): 1892-1895.

PubMed Abstract | Publisher Full Text

5. Wang DS, Chen DL, Ren C, et al:: ABO blood group, hepatitis $\mathbf{B}$ viral infection and risk of pancreatic cancer. Int J Cancer. 2012; 131(2): 461-8. PubMed Abstract | Publisher Full Text

6. Lindesmith L, Moe C, Marionneau S, et al:: Human susceptibility and resistance to Norwalk virus infection. Nat Med. 2003; 9(5):548-53. PubMed Abstract | Publisher Full Text

7. Loscertales MP, Owens S, O'Donnell S, et al:: ABO blood group phenotypes and Plasmodium falciparum malaria: unlocking a pivotal mechanism. Adv Parasitol. 2007; 65: 1-50.

PubMed Abstract | Publisher Full Text

8. Göker H, Karakulak EA, Demiroğlu H, et al.: The effects of blood group types on the risk of COVID-19 infection and its clinical outcome. TurkJ Med Sci. 2020; 50(4): 679-83.

PubMed Abstract | Publisher Full Text | Free Full Text

9. Dzik S, Eliason K, Morris EB, et al.: COVID-19 and ABO blood groups. Transfusion. 2020; 60(8): 1883-1884.

PubMed Abstract | Publisher Full Text | Free Full Text

10. Mendy A, Keller JL, Apewokin S, et al.: Is Blood Type Associated with COVID-19 Severity? medRxiv. 2020; 2020.08.11.20172676.

PubMed Abstract | Publisher Full Text | Free Full Text
11. Wu Y, Feng Z, LI P, et al.: Relationship between ABO blood group distribution and clinical characteristics in patients with COVID-19. Clin Chim Acta. 2020; 509: 220-223.

PubMed Abstract | Publisher Full Text

12. Zhao J, Yang $Y$, Huang $\mathrm{H}$, et al.: Relationship between the ABO Blood Group and the COVID-19 Susceptibility. medRxiv. 2020; 2020.03.11.20031096. Publisher Full Text

13. Zietz M, Zucker J, Tatonetti NP: Testing the association between blood type and COVID-19 infection, intubation, and death. medRxiv. 2020; 2020.04 .08 .20058073

PubMed Abstract | Publisher Full Text | Free Full Text

14. Latz CA, DeCarlo C, Boitano L, et al.: Blood type and outcomes in patients with COVID-19. Ann Hematol. 2020; 99(9): 2113-2118. PubMed Abstract | Publisher Full Text | Free Full Text

15. Hoiland RL, Fergusson NA, Mitra AR, et al:: The association of ABO blood group with indices of disease severity and multiorgan dysfunction in Covid-19. Blood Adv. 2020; 4(20): 4981-4989. PubMed Abstract | Publisher Full Text | Free Full Text

16. Barnkob $M B$, Pottegård $A$, Støvring $\mathrm{H}$, et al: Reduced prevalence of SARS-CoV2 infection in ABO blood group O. Blood Advances. 2020; 4(20): 4990-4993.

PubMed Abstract | Publisher Full Text | Free Full Text

17. Guillon $\mathrm{P}$, Clément $\mathrm{M}$, Sébille $\mathrm{V}$, et al.: Inhibition of the interaction between the SARS-CoV spike protein and its cellular receptor by anti-histo-blood group antibodies. Glycobiology. 2008; 18(12): 1085-1093. PubMed Abstract | Publisher Full Text | Free Full Text

18. Ellinghaus D, Degenhardt F, Bujanda L, et al.: Genomewide Association Study of Severe Covid-19 with Respiratory Failure. N EnglJ Med. 2020; 383(16): 1522-1534.

PubMed Abstract | Publisher Full Text | Free Full Text

19. Al-Fahad D, Vaiyapuri S: Blood types and their relationship with COVID-19 among a study population in Iraq. University of Reading. Dataset. 2020 http://www.doi.org/10.17864/1947.278 


\section{Open Peer Review}

\section{Current Peer Review Status:}

\section{Version 1}

Reviewer Report 09 February 2021

https://doi.org/10.5256/f1000research.30717.r77833

(C) 2021 Jones S. This is an open access peer review report distributed under the terms of the Creative Commons Attribution License, which permits unrestricted use, distribution, and reproduction in any medium, provided the original work is properly cited.

\section{Sarah Jones}

Department of Life Sciences, Manchester Metropolitan University, Manchester, UK

In this brief report, Majeed and colleagues investigate the relationship between blood groups and COVID19 susceptibility and severity. The study analyses data from 5668 COVID19 patients admitted to two hospitals in Iraq, and an equal number of matched controls admitted to the same hospitals during the study period. The study compares the frequency of blood groups in the study population and the proportions of controls and COVID19 patients within each blood type. The results demonstrate that within the O+ blood type, the proportion of COVID19 patients is significantly lower compared to controls, indicating reduced susceptibility to the virus. In contrast, in blood types $A-, B-, A B-, O-$ and $A B+$ there is a higher proportion of COVID19 cases compared to controls, suggesting increased susceptibility. No relationship was found between blood group and disease severity. The methods are clearly reported, and the data appears sound.

The report would benefit from a demographics table or information specifically relating to ethnicity. It has been established that ethnicity impacts susceptibility to SARs-CoV-2 and the distribution of blood groups vary between ethnic groups. Does the data represent a difference in ethnicity rather than blood group? And might this explain conflicting results with larger published studies concerning RhD status and COVID19 susceptibility?

A few minor points to improve clarity:

It is clearly stated that $\mathrm{O}+$ was the most common blood type in the control population, it would be useful to have a similar statement for the COVID19 group, stating the most common blood type.

Also, to improve clarity it would be useful to present the data comparing the percentage of patients that are RhD- in each group. It appears to be more than double in the COVID19 group (Control 4\%; COVID19 9.1\%).

The final statement, emphasising the factors likely to be responsible for the associations observed between the blood types and COVID19 requires further clarification and supporting citations. What is the evidence that the proportion of each blood type varies in different occupations or geographical locations? Were the study groups not all from the 
same geographical location (local to the hospitals)? Presenting the ethnicity information for the study group would also help to address this point.

Is the work clearly and accurately presented and does it cite the current literature? Yes

Is the study design appropriate and is the work technically sound?

Yes

Are sufficient details of methods and analysis provided to allow replication by others? Yes

If applicable, is the statistical analysis and its interpretation appropriate?

Yes

Are all the source data underlying the results available to ensure full reproducibility? Yes

Are the conclusions drawn adequately supported by the results?

Partly

Competing Interests: No competing interests were disclosed.

Reviewer Expertise: haematology, platelets, thrombosis, endothelial cells

I confirm that I have read this submission and believe that I have an appropriate level of expertise to confirm that it is of an acceptable scientific standard.

The benefits of publishing with F1000Research:

- Your article is published within days, with no editorial bias

- You can publish traditional articles, null/negative results, case reports, data notes and more

- The peer review process is transparent and collaborative

- Your article is indexed in PubMed after passing peer review

- Dedicated customer support at every stage

For pre-submission enquiries, contact research@f1000.com 